\title{
Microstructure and Mechanical Properties of Co-Cr-Mo-Si-Y-Zr High Entropy Alloy
}

\author{
Karsten Glowka ${ }^{1}{ }^{(}$, Maciej Zubko ${ }^{1,2, *} \mathbb{D}$, Paweł Świec ${ }^{1}$, Krystian Prusik $^{1}{ }^{1}$,

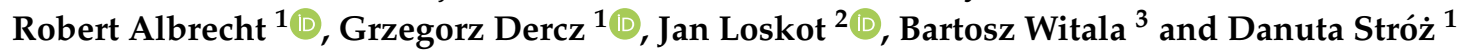 \\ 1 Institute of Materials Engineering, University of Silesia in Katowice, 75 Pułku Piechoty 1A St., \\ 41-500 Chorzów, Poland; karsten.glowka@us.edu.pl (K.G.); pawel.swiec@us.edu.pl (P.Ś.); \\ krystian.prusik@us.edu.pl (K.P.); robert.albrecht@us.edu.pl (R.A.); grzegorz.dercz@us.edu.pl (G.D.); \\ danuta.stroz@us.edu.pl (D.S.) \\ 2 Department of Physics, Faculty of Science, University of Hradec Králové, Rokitanského 62, \\ 50003 Hradec Králové, Czech Republic; jan.loskot@uhk.cz \\ 3 Faculty of Materials Engineering, Silesian University of Technology, Krasińskiego 8, 40-019 Katowice, \\ Poland; bartosz.witala@polsl.pl \\ * Correspondence: maciej.zubko@us.edu.pl; Tel.: +48-32-349-75-09
}

Received: 14 October 2020; Accepted: 27 October 2020; Published: 30 October 2020

\begin{abstract}
Presented work was focused on obtaining new, up to our knowledge, non-described previously in the literature high entropy $\mathrm{Co}_{15} \mathrm{Cr}_{15} \mathrm{Mo}_{25} \mathrm{Si}_{15} \mathrm{Y}_{15} \mathrm{Zr}_{15}$ alloy to fill in the knowledge gap about the six-elemental alloys located in the adjacent to the center of phase diagrams. Material was obtained using vacuum arc melting. Phase analysis revealed the presence of a multi-phase structure. Scanning electron microscopy microstructure analysis revealed the existence of three different phases with partially dendritic structures. Chemical analysis showed that all phases consist of all six principal elements-however, with different proportions. Transmission electron microscopy microstructure analysis confirmed the presence of amorphous and nanocrystalline areas, as well as their mixture. For the studied alloy, any phase transformation and solid-state crystallization were not revealed in the temperature range from room temperature up to $1350^{\circ} \mathrm{C}$. Nanoindentation measurements revealed high nanohardness (13(2) GPa and 18(1) GPa for dendritic and interdendritic regions, respectively) and relatively low Young's modulus (185(23) GPa and 194(9) GPa for dendritic and interdendritic regions, respectively) of the observed phases.
\end{abstract}

Keywords: multi-component alloys; high entropy alloys; microstructure analysis; mechanical properties

\section{Introduction}

High entropy alloys (HEAs) belong to the group of multi-principal-element materials composed of more than five chemical elements. They have been known in the literature since 2004; however, background works began much earlier-in the late 1970s [1,2]. HEAs have gained much attention in recent years due to their interesting and promising properties in comparison to conventional alloys; by 2018, over 900 papers describing high entropy alloys were reported [3]. However, only about 140 high entropy compositions exhibit a single-phase structure [3]. The first high entropy composition described in the literature by Cantor et al. [1] was a single-phase, faced-centered cubic (FCC), five elemental, equiatomic $\mathrm{Co}_{20} \mathrm{Cr}_{20} \mathrm{Fe}_{20} \mathrm{Mn}_{20} \mathrm{Ni}_{20}$ alloy. In the same year, other studies on high entropy alloys were reported [4-8].

As it was mentioned, HEAs exhibit promising properties, which can promote their industrial applications. Zhang et al. proposed that the five elemental, high entropy alloy FeCoNi(AlSi) $)_{x}$ 
$(0 \leq x \leq 0.8$ mol.\%), thanks to its excellent magnetic, electrical, and mechanical properties, can be used as a soft magnetic material [9]. On the other hand, the cantor alloy (CrMnFeCoNi), due to exceptional damage tolerance with tensile strengths above $1 \mathrm{GPa}$ and fracture toughness values exceeding $200 \mathrm{MPa} \cdot \mathrm{m}^{1 / 2}$, is suitable for cryogenic applications at liquid nitrogen temperatures [10]. Eutectic high entropy alloys such as $\mathrm{AlCoCrFeNi}_{2.1}$ (at.\%) also exhibit excellent microstructure stability and mechanical properties up to $700{ }^{\circ} \mathrm{C}$ [11]. Additionally, HEAs containing refractory elements such as $\mathrm{Ta}, \mathrm{V}$, and $\mathrm{W}$ (e.g., MoNbTaVW) exhibit high melting points and microstructural stability at elevated temperatures and, thus, are promising candidates for high-temperature applications [12]. Moreover, it was reported that some refractory elements such as $\mathrm{Ti}, \mathrm{Zr}$, or Nb exhibit good biocompatibility and high corrosion resistance [13], which means that high entropy alloys (e.g., TiZrNbTaMo) can be also proposed as materials for biomedical applications [14]. Furthermore, some HEAs (e.g., NiTiTaCoCu) are shape memory alloys. as they exhibit thermoelastic martensitic transformation $[15,16]$. The group of high entropy shape memory alloys also includes ((TiZrHf) $\left.{ }_{50} \mathrm{Ni}_{25} \mathrm{Co}_{10} \mathrm{Cu}_{15}\right)$ described by Chen et al. [17].

High entropy alloys could be defined based on two criteria. The first definition based on chemical composition is described in one of the earliest publications concerning HEAs and says that "high entropy alloy is a material composed with five or more principal alloying elements in equimolar ratios" [8]. The requirement for equimolar concentrations is restrictive; however, in the same paper, the authors make some expansion of this definition to include "principal elements with the concentration of each element being between 5 and 35 at.\%" [8].

The second definition is based on configurational entropy $\left(\Delta S_{\text {conf }}\right)$ and characterizes HEAs as "materials with $\left(\Delta \mathrm{S}_{\text {conf }}\right) \geq 1.61 \mathrm{R}(\mathrm{R}$-gas constant) no matter whether they are single-phase or multiphase at room temperature". Based on this, it is possible to separate groups of low entropy alloys $\left(\Delta \mathrm{S}_{\text {conf }}<0.69 \mathrm{R}\right)$, medium entropy alloys $\left(0.69 \mathrm{R}<\Delta \mathrm{S}_{\text {conf }}<1.61 \mathrm{R}\right)$, and high entropy alloys $\left(\Delta \mathrm{S}_{\text {conf }} \geq 1.61 \mathrm{R}\right)$ [18]. The Boltzmann equation is very helpful to give a simple approach to estimate $\Delta \mathrm{S}_{\text {conf }}$ from the alloy composition; however, it assumes a purely random atom distribution in the crystal lattice. Unfortunately, this situation rarely occurs in metallic solutions. Therefore, in order to avoid doubts, a mixing entropy parameter $\left(\Delta S_{\text {mix }}\right)$ was used instead of configurational entropy [19]. Configurational entropy is not enough to describe the formation of solid solution (SS) in high entropy alloys. For a binary alloy, the SS formation mechanism can be described by the well-known Hume-Rothery rules (H-R rules). Thanks to increasing the knowledge about HEAs, extensions of the $\mathrm{H}-\mathrm{R}$ rules were developed to the SS formation in high entropy alloys. For instance, differences in the atomic radii of alloying elements denoted as the atomic size mismatch parameter $\delta$ was defined and described by Takeuchi et al. [20]. It was shown that, for single-phase solid solution formation, the atomic size mismatch parameter should not exceed the critical value of $\delta<5.0 \%$ [20]. Additionally, an amorphous phase formation is predicted for $\delta>8.60 \%$ [21]. Mixing the enthalpy $\left(\Delta \mathrm{H}_{\text {mix }}\right)$ of alloying elements has also an influence on the solid solution formation [22]. It was predicted that mixing enthalpy should be in $-15 \leq \Delta \mathrm{H}_{\text {mix }} \leq 5 \mathrm{~kJ} \cdot \mathrm{mol}^{-1}$ range for SS formation [22]. The electronegativity parameter has also an influence on HEA solid solution formations, as in the case of binary alloys (H-R rules). This parameter was described by Nong et al. and denoted as $\Delta x$ [23]. For solid solution formation in high entropy alloys, $\Delta x$ should be in the range of $-15 \leq \Delta \chi \leq 5 \mathrm{eV}$ [24]. The valence electron concentration (VEC) parameter must be also taken in to account for when the solid solution formation in HEAs is considered [25]. For VEC $<6.87$, the formation of a solid solution with a body-centered cubic (BCC) structure is predicted. Formation of a solid solution of a faced-centered cubic (FCC) structure can be expected when VEC $\geq 8$ 8.0. For valence electrons concentration values in the range of $6.87 \leq \mathrm{VEC}<8.0$, the mixture of BCC and FCC structures is expected [25]. It is worth mentioning that all the above-described parameters do not take into account the temperature factor in SS formation; however, they are essential in the calculations of other thermodynamic parameters, like the $\Omega$ parameter introduced by Yang et al. [26]. The $\Omega$ parameter describing the formation of a solid solution is based on the empirical melting point of an alloy $\left(\mathrm{T}_{\mathrm{m}}\right)$, mixing entropy $\left(\Delta \mathrm{S}_{\mathrm{mix}}\right)$, and mixing enthalpy $\left(\Delta \mathrm{H}_{\text {mix }}\right)$. They proposed $\Omega=1$ as a critical value to obtain a single-phase solid solution. If $\Omega>1$, 
multi-phase HEAs are mainly formed. Moreover, for $\Omega \leq 1$, intermetallic compounds and segregations are observed [26]. Further studies on solid-solution creations in HEAs indicated that the atomic packing fraction of a unit cell has also a great influence on the different type of structure formations after solidification. Such a study was performed by Ye et al. They proposed a thermodynamic parameter denoted as $\phi$ [27]. In calculations of the $\phi$ parameter, the ideal configurational entropy of mixing using Boltzmann's constant $\left(\mathrm{S}_{\mathrm{c}}\right)$, mixing enthalpy $\left(\Delta \mathrm{H}_{\mathrm{mix}}\right)$, empirical melting point of an alloy $\left(\mathrm{T}_{\mathrm{m}}\right)$, and excess mixing entropy $\left(\mathrm{S}_{\mathrm{E}}\right)$ is used. Excess mixing entropy was introduced as a new variable, which can be proposed as a supplement of the ideal configurational entropy of mixing $\left(\Delta S_{\text {mix }}\right)$ [3]. $\mathrm{S}_{\mathrm{E}}$ describes the changes in mixing entropy depending on the atomic packing fraction $(\xi)$. Atomic packing fraction mainly takes values of 0.68 and 0.74 , which correspond to the atomic packing fractions in BCC/HCP (hexagonal closest packed) (74\%) and FCC (68\%) structures, respectively. Moreover, excess mixing entropy is always negative and corresponds to atomic sizes influencing the atomic packing fraction of a unit cell [27]. Geometrical description of the solid solution formation has also been performed. Atomic packing misfit and topological instability was described by Wang et al. and denoted as $\gamma$ [28]. For binary alloys, it was shown that the critical value of an atom misfit is $\gamma=1.167$, which corresponds to $15 \%$ atomic size differences between the alloying elements proposed by Hume-Rothery [28]. For multi-component alloys, including HEAs, $\gamma<1.175$ determines the solubility of multiple elements. Amorphous high entropy alloys (high entropy bulk metallic glasses) also bring a lot of attention. Inoue in 2000 created empirical rules for the formation of amorphous phases for bulk metallic glasses, but the same rules have been also adopted for amorphous-phase high entropy alloy formations. Inoue's rules include: (1) the alloy system contains at least three elements, (2) the mixing enthalpy among the principal elements has a large and negative value, and (3) the atomic size difference among the major constituent elements is larger than 12\% [29]. As it can be noticed, Inoue's rules are mainly focused on atomic size differences between alloying elements and mixing enthalpy, which correspond to the above-described $\delta$ and $\Delta \mathrm{H}_{\text {mix }}$ parameters, respectively.

The selection of the appropriate alloying elements is also critical in the formation of amorphous phases. It was reported that glass-forming ability (GFA) elements can be categorized into three groups based on their atomic radii: (1) small metalloids (C, B, and $\mathrm{Si}$ ); (2) intermediate transition metals (Fe, Ni, $\mathrm{Co}, \mathrm{Cu}, \mathrm{Mo}, \mathrm{Zn}, \mathrm{Nb}, \mathrm{Ta}$, and Ti); and (3) large elements (Zr, Sn, Sc, Sb, Y, La, and Ca) [30]. Si addition as a small metalloid element is effective in glass formation for refractory alloys such as $\mathrm{Cu}, \mathrm{Fe}$, and $\mathrm{Ni}$ alloys [31-33]. The amorphization ability of Si can be visible for the $\mathrm{Cu}_{47} \mathrm{Ti}_{34} \mathrm{Zr}_{11} \mathrm{Ni}_{8}$ alloy, where a substitution of $1 \% \mathrm{Ti}$ by Si increased the amorphous volume fraction [31]. On the other hand, silicon additions in $\mathrm{Zr}$-based alloys are detrimental, due to the formation of silicates [30]. The amorphous ability of Si were also reported for Co-Fe-Ta-B bulk metallic glass, where the Si addition favors a glassy formation and, also, improves the mechanical properties [34]. It was also reported that the addition of large elements such as $\mathrm{Y}$ also increased the amorphous volume fraction. For instance, in the case of the $\left(\mathrm{Cu}_{60} \mathrm{Zr}_{30} \mathrm{Ti}_{10}\right)_{100-x} \mathrm{M}_{x}$ alloy, an addition of only $2 \%$ of $\mathrm{Y}$ increased the amorphous volume fraction [35]. The same phenomenon was also reported for $\mathrm{Fe}_{63-x} \mathrm{Zr}_{8} \mathrm{Co}_{6} \mathrm{Al}_{1} \mathrm{Mo}_{7} \mathrm{~B}_{15} \mathrm{M}_{x}$, where $x=1.5-2 \%$ of $\mathrm{Y}$ significantly increased the amorphous volume fraction [36,37]. Improvement of the glassy formation ability by $\mathrm{Y}$ was also reported for $\left(\mathrm{Fe}_{72} \mathrm{Nb}_{4} \mathrm{~B}_{20} \mathrm{Si}_{4}\right)_{100-x} \mathrm{Y}_{x}(x=0-5)$ [38]. Other independent studies also revealed a high level of glass formability for $\mathrm{Cu}-\mathrm{Hf}-\mathrm{Ti}$ alloys by a small addition of Si and Y (from 0.1 to 1 at.\%) [39].

HEAs compositions can be described in the N-elemental composition space within a (N-1)-dimensional simplex (N-1 dimensional solids) [3]. Conventional alloys (with two or more alloying elements) are mainly located at the corners of phase diagrams in comparison to equiatomic HEAs located at the center of the phase diagram. Non-equiatomic HEAs ale mainly located adjacent to the center of the phase diagram [22]. It can be calculated that there can be 7059052 possible high entropy compositions containing six alloying elements [3]. The presented work was focused on obtaining a new, up to our knowledge, non-described previously in the literature multi-component $\mathrm{Co}_{15} \mathrm{Cr}_{15} \mathrm{Mo}_{25} \mathrm{Si}_{15} \mathrm{Y}_{15} \mathrm{Zr}_{15}$ high entropy alloy. 
Additionally, the main aim of the performed studies was also to fill in the knowledge gap about the six-elemental alloys located adjacent to the center of the phase diagrams. The material was obtained using the vacuum arc melting method and characterized on various scale levels-from a macro- to nanoscale. In the presented work, we wanted to learn whether, based only on the proposed thermodynamic parameters, it is possible to obtain an amorphous alloy in a bulk form immediately after the arc melting process (after solidification). The detailed characterization of the new $\mathrm{Co}_{15} \mathrm{Cr}_{15} \mathrm{Mo}_{25} \mathrm{Si}_{15} \mathrm{Y}_{15} \mathrm{Zr}_{15}$ high entropy alloy could contribute to the development of amorphous high entropy alloys.

\section{Materials and Methods}

The composition of the proposed high entropy alloy $\left(\mathrm{Co}_{15} \mathrm{Cr}_{15} \mathrm{Mo}_{25} \mathrm{Si}_{15} \mathrm{Y}_{15} \mathrm{Zr}_{15}\right)$ was determined by the performed thermodynamical calculation. The alloying elements were chosen by taking into account their different atomic radii and different melting points (see Table 1). Thermodynamic calculations were carried out in order to fulfil all criteria for HEAs (Table 2). Additionally, silicon (Si) and yttrium (Y) were chosen as amorphization ability elements [30].

Table 1. Physical properties of pure alloying elements: crystal structure, atomic radius $\left(\mathrm{r}_{\mathrm{i}}\right)$, valence electron concentration $(\mathrm{VEC})_{\mathrm{i}}$, melting point $(\mathrm{Tm})_{\mathrm{i}}$, and Pauling's electronegativity $\left(\mathrm{X}_{\mathrm{i}}\right)[40,41]$. BCC: body-centered cubic, FCC: face-centered cubic and HCP: hexagonal closest packed.

\begin{tabular}{cccccc}
\hline Element & Crystal Structure & $\mathbf{r}_{\mathbf{i}}(\mathbf{\AA})$ & $\mathbf{~ ( V E C ) ~}_{\mathbf{i}}$ & $\mathbf{( T m}_{\mathbf{I}} \mathbf{( K )}$ & $\boldsymbol{\chi}_{\mathbf{i}}$ (Pauling Units) \\
\hline Co & HCP & 1.251 & 9 & 1768 & 1.88 \\
Cr & BCC & 1.249 & 6 & 2180 & 1.66 \\
Mo & BCC & 1.363 & 6 & 2896 & 2.16 \\
Si & FCC & 1.153 & 4 & 1687 & 1.90 \\
Y & HCP & 1.802 & 3 & 1798 & 1.22 \\
Zr & HCP & 1.603 & 4 & 2123 & 1.33 \\
\hline
\end{tabular}

Table 2. Thermodynamic parameters calculated for the $\mathrm{Co}_{15} \mathrm{Cr}_{15} \mathrm{Mo}_{25} \mathrm{Si}_{15} \mathrm{Y}_{15} \mathrm{Zr}_{15}$ alloy: atomic size mismatch $(\delta)$, mixing enthalpy $\left(\Delta \mathrm{H}_{\text {mix }}\right)$, mixing entropy $\left(\Delta \mathrm{S}_{\text {mix }}\right)$, electronegativity differences $(\Delta \chi)$, valence electron concentration (VEC), Yang et al. parameter $(\Omega)$, Ye et al. parameter $(\phi)$, atomic packing misfit, and topological instability parameter $(\gamma)$.

\begin{tabular}{|c|c|c|c|c|c|c|c|c|}
\hline \multirow{2}{*}{$\delta(\%)$} & \multirow{2}{*}{$\Delta \mathrm{H}_{\text {mix }}\left(\mathrm{kJ} \cdot \mathrm{mol}^{-1}\right)$} & \multirow{2}{*}{$\Delta S_{\operatorname{mix}}\left(\mathrm{J}(\mathrm{mol} \cdot \mathrm{K})^{-1}\right)$} & \multirow{2}{*}{$\begin{array}{c}\Delta x \\
(\mathrm{eV})\end{array}$} & \multirow{2}{*}{ VEC } & \multirow{2}{*}{$\Omega[26]$} & \multicolumn{2}{|c|}{$\Phi[27]$} & \multirow{2}{*}{$\gamma[28]$} \\
\hline & & & & & & $\xi=0.68$ & $\xi=0.74$ & \\
\hline 15.44 & -29.49 & $\begin{array}{c}14.71 \\
(1.769 \cdot \mathrm{R})\end{array}$ & 0.34 & 5.40 & 1.08 & 2.80 & 1.73 & 1.626 \\
\hline
\end{tabular}

For the studied alloy, all the above-described thermodynamic parameters for the solid solution formation were also calculated. The obtained values are presented in Table 2. The results, especially atomic size mismatch parameter $(\delta)$ and mixing enthalpy $\left(\Delta \mathrm{H}_{\mathrm{mix}}\right)$, confirmed that of all the above-described, Inoue's conditions of amorphous phase formation were met.

A six-elemental composition alloy $\left(\mathrm{Co}_{15} \mathrm{Cr}_{15} \mathrm{Mo}_{25} \mathrm{Si}_{15} \mathrm{Y}_{15} \mathrm{Zr}_{15}\right)$ was prepared from bulk elements (purity $\geq 99 \%$ ). Elemental pieces were mixed and melted using a vacuum arc melting (VAM) technique (Institute of Materials Engineering, Chorzów, Poland) in an argon protective gas atmosphere. The appropriate cooling rate was achieved by a water-cooled copper crucible. High-purity Ti was used as a Ti-getter for residual gases in a vacuum chamber (chamber pressure level was 1.2 bar). The obtained alloy was prepared in the form of a button of $\sim 10 \mathrm{~mm}$ thick and $\sim 6.5 \mathrm{~mm}$ in diameter. Weight of the button was $\sim 6.5 \mathrm{~g}$. In order to achieve a homogeneous distribution of elements, the obtained button was remelted ten times for about $180 \mathrm{~s}$ and flipped over for each remelting stage. No further thermal treatment was performed. Subsequently, the sample was embedded into resin and ground using SiC grinding papers with different grain sizes (grit from 320 to 4000). After grinding, the sample 
was polished using diamond suspensions with grain sizes from $6 \mu \mathrm{m}$ to $1 \mu \mathrm{m}$. Final polishing was performed using colloidal silica oxide $\left(\mathrm{SiO}_{2}\right)$ suspension with $0.04-\mu \mathrm{m}$ grain size.

The X-ray powder diffraction (XRD) measurements were carried out using a Panalytical Empyrean diffractometer (Malvern Instruments, Malvern, UK) with $\mathrm{Cu}$ anode with a wavelength of 1.54056 $\AA$ working at an electric current of $30 \mathrm{~mA}$ and voltage of $40 \mathrm{kV}$ and equipped with a PIXcell ${ }^{3 \mathrm{D}}$ detector (Malvern Instruments, Malvern, UK). The XRD patterns were collected in the angular range of $2 \theta=15-145^{\circ}$ with $0.02^{\circ}$ steps. The phase analysis was performed using reference standards from the International Centre for Diffraction Data (ICDD) PDF-4 database. The microstructure analysis was performed using the JEOL JSM-6480 (JEOL Ltd., Tokyo, Japan) scanning electron microscope (SEM) working with the accelerating voltage of $20 \mathrm{kV}$ equipped with the energy-dispersive $X$-ray spectroscopy (EDS) detector (IXRF, Austin, TX, USA) from IXRF. The structure of the alloy was also studied using JEOL JEM-3010 high-resolution transmission electron microscope (HR TEM, JEOL Ltd., Tokyo, Japan) with 300-kV acceleration voltage, equipped with a Gatan $2 \mathrm{k} \times 2 \mathrm{k}$ Orius ${ }^{\mathrm{TM}} 833 \mathrm{SC} 200 \mathrm{D}$ CCD camera (Gatan Inc. Pleasanton, CA, USA) and the energy-dispersive X-ray spectroscopy (EDS) detector from Oxford Instruments Company (Oxford Instruments Company, Abingdon, UK). Thin foil samples for TEM measurements were cut with a diameter $\mathrm{d}=3 \mathrm{~mm}$ and $\sim 100-\mu \mathrm{m}$ thickness from the central part of the VAM bullet. Next, the samples were ground on both sides and Ar-ion polished on the Gatan Precision Ion Polishing System (PIPS) (Gatan Inc. Pleasanton, CA, USA). Beam energy was changed in the range of 4 to $2.5 \mathrm{keV}$ in order to reduce the risk of an amorphous layer forming on the surface of a thin foil sample. In addition, the angular range of the ion guns varied from $4^{\circ}$ to $1^{\circ}$ with the beam energy changes. The recorded TEM selected area electron diffraction (SAED) patterns were indexed using the ElDyf computer software (version 2.1, Institute of Materials Engineering, Chorzów, Poland). High-temperature differential scanning calorimetry (HT DSC) measurements were performed using Netzsch Pegasus 404 F1 (NETZSCH Holding, Selb, Germany) in the temperature range from room temperature (RT) up to $1350^{\circ} \mathrm{C}$, with a $5-\mathrm{K} / \mathrm{min}$ heating/cooling rate. HT DSC measurements were carried out under an argon protective gas atmosphere, with $20-\mathrm{mL} / \mathrm{min}$ gas flow. The studied and reference samples were measured in $\mathrm{Al}_{2} \mathrm{O}_{3}$ crucibles. Nanohardness test was performed using Hysitron TI 950 Triboindenter (Bruker, Billerica, MA, USA) equipped in Berkovich tip with a total included angle $\sim 142^{\circ}$ under the static load $500 \mu \mathrm{N}$.

\section{Results and Discussion}

\subsection{Phase Analysis}

The performed phase analysis revealed the presence of four crystalline phases-two hexagonal and two cubic phases. They were identified by X-ray diffraction phase analysis (Figure 1) based on the standards from ICDD database. 


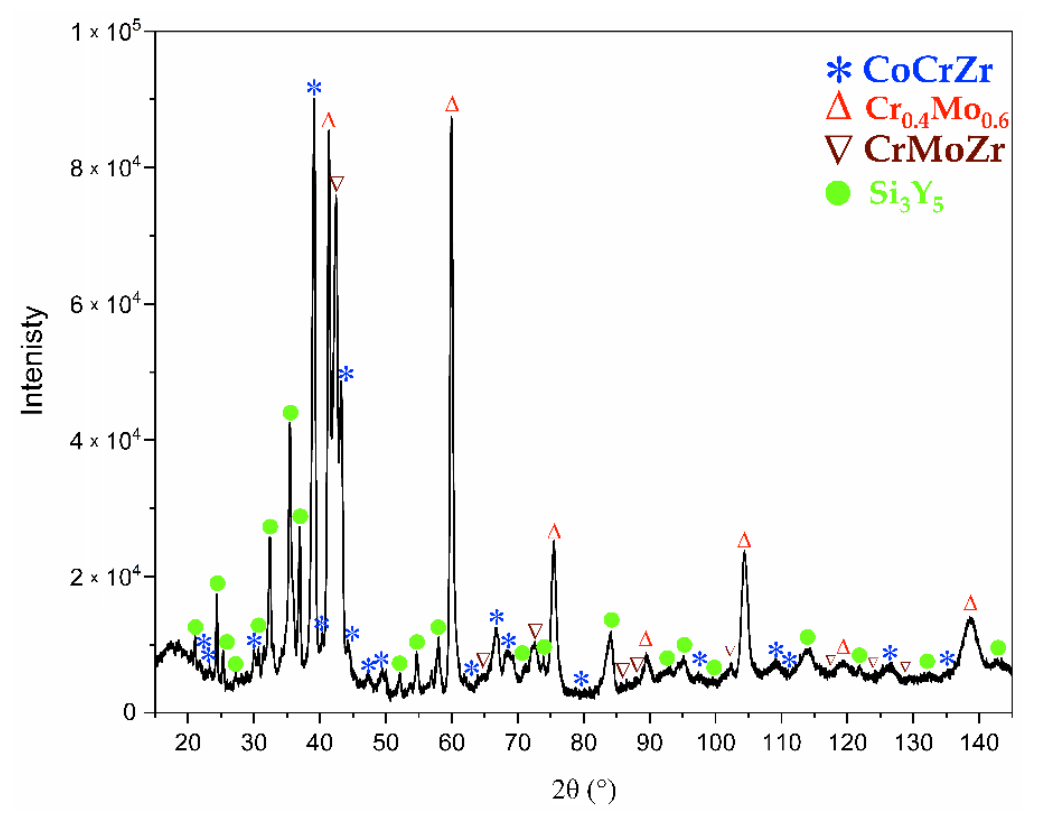

Figure 1. X-ray diffraction pattern for the studied $\mathrm{Co}_{15} \mathrm{Cr}_{15} \mathrm{Mo}_{25} \mathrm{Si}_{15} \mathrm{Y}_{15} \mathrm{Zr}_{15}$ alloy with indexed phases.

The first identified phase was the hexagonal phase with a structure similar to $\mathrm{Si}_{3} \mathrm{Y}_{5}$ (ICDD 04-001-2096) with space group $\mathrm{P}_{3} / \mathrm{mcm}$ and lattice parameters $\mathrm{a}_{0}=8.44 \AA$ and $\mathrm{c}_{0}=6.35 \AA$. The highest intensity peak was obtained for $2 \theta=35^{\circ}$ and represents $\{112\}$ planes, with ICCD interplanar distance $\mathrm{d}_{\mathrm{hkl}}=2.53 \AA$. The second identified phase was a hexagonal CoCrZr-like structure (ICDD 04-003-7686) with space group $P 6_{3} / m m c$ and lattice parameters from ICCD are $\mathrm{a}_{0}=5.00 \AA$ and $\mathrm{c}_{0}=8.20 \AA$. The highest intensity peak for that structure was revealed for $2 \theta=39^{\circ}$, which corresponds to $\{200\}$ planes, with ICDD interplanar distance $d_{h k l}=2.17 \AA$. The third of the identified phases was the cubic phase with a structure similar to $\mathrm{Cr}_{0.4} \mathrm{Mo}_{0.6}$ (ICDD 04-018-6044), with space group $\operatorname{Im} \overline{3} \mathrm{~m}$ and $\mathrm{a}_{0}=3.07 \AA$ ICDD lattice parameter. The highest intensity peak was obtained for $2 \theta=59^{\circ}$, which also corresponds to $\{200\}$ planes with ICDD interplanar distance $\mathrm{d}_{\mathrm{hkl}}=1.54 \AA$. The fourth was the cubic phase structure similar to $\mathrm{CrMoZr}$ (ICDD 04-015-0011) with space group $\mathrm{Fm} \overline{3} \mathrm{~m}$ and lattice parameters $\mathrm{a}_{0}=3.39 \AA$. . The highest intensity peak was obtained for $2 \theta=42^{\circ}$, which corresponds to $\{222\}$ planes with interplanar distance $\mathrm{d}_{\mathrm{hkl}}=2.13 \AA$.

For the $\mathrm{Cr}_{0.4} \mathrm{Mo}_{0.6}$-like phase, the $\mathrm{X}$-ray-diffraction pattern revealed that peaks were slightly shifted towards lower diffraction angles. It means that there is the increase of the lattice parameter comparing what can be associated with the unit cell expansion due to the presence of higher atomic radii atoms like $Y(\sim 1.80 \AA)$. Additionally, due to the highest intensity for peak $2 \theta=60^{\circ}$ in comparison to other peaks, the presence of texture is highly probable. No significant diffraction peak shifts were observed for the $\mathrm{CrMoZr}$ phase. Only for peak $2 \theta=72^{\circ}$ representing the $\{440\}$ plane peak was widening observed. It may correspond to a strain in the crystal structure. For the CoCrZr-like phase and $\mathrm{Si}_{3} \mathrm{Y}_{5}$-like phase, no significant peak shifts and/or widening were observed. Additionally, the XRD pattern revealed raised backgrounds in the $2 \theta=15^{\circ}-25^{\circ}$ and $2 \theta=30^{\circ}-47^{\circ}$ regions, which could correspond to the presence of amorphous fractions. In order to confirm the observation, detailed HR TEM studies were performed.

Although the Inoue rules of bulk metallic glasses were fulfilled, the obtained material is mostly crystalline. It is known that the cooling rate has a great influence on the alloy structure formation. A glassy structure forms due to freezing the undercooled liquid to the glass transition temperature $\mathrm{T}_{\mathrm{g}}$. To prevent the transition from a liquid to a crystalline phase, a critical cooling rate has to be exceeded. High cooling rates of $10^{5}-10^{6} \mathrm{~K} \cdot \mathrm{s}^{-1}$ are required to obtain the amorphous phase [42]. Additionally, up to now, amorphous alloys were obtained by fabrication methods, which ensure reaching a critical 
cooling rate such as: suction casting (e.g., $\mathrm{Ti}_{16.7} \mathrm{Zr}_{16.7} \mathrm{Hf}_{16.7} \mathrm{Cu}_{16.7} \mathrm{Ni}_{16.7} \mathrm{Be}_{16.7}$ [43]) or melt spinning (e.g., $\mathrm{Pd}_{20} \mathrm{Pt}_{20} \mathrm{Cu}_{20} \mathrm{Ni}_{20} \mathrm{P}_{20}$ [44]).

\subsection{SEM Microstructure Studies}

The microstructure analysis performed using SEM confirmed the presence of a multiphase microstructure. The backscattered electrons contrast image (BSE) (Figure 2) revealed the presence of three phases with different contrasts correlated with the different chemical compositions. The phases were denoted as follows: dendrites, "light-grey", and "dark-grey". The fourth phase revealed by X-ray phase analysis was not visible in the BSE image. It is probably due to the fact that there is only a slight difference in the contrast between this phase and one of the others present in the sample. It should be also noted that the alloy microstructure also revealed the presence of pores.

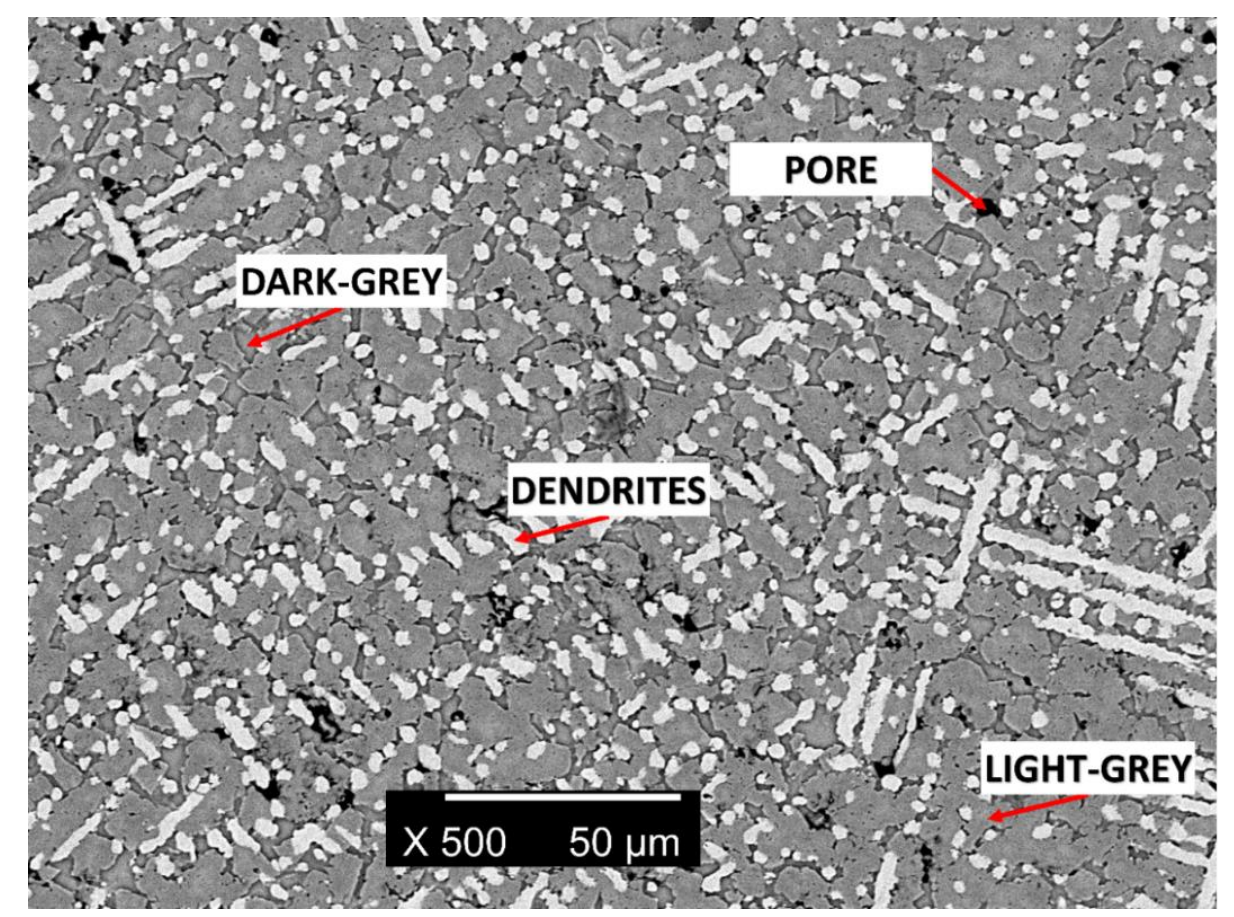

Figure 2. Backscattered electrons contrast image (BSE) of the sample microstructure with the assigned phases and pores.

A chemical composition analysis was performed using the EDS technique. For all identified phases, the EDS studies confirmed the presence of all six principal elements. The chemical composition results obtained for all phases are presented in Table 3.

Table 3. SEM energy-dispersive X-ray spectroscopy (EDS) chemical composition (at.\%) of all phases in the studied alloy.

\begin{tabular}{ccccccc}
\hline Studied Area & Co & Cr & Mo & Si & Y & Zr \\
\hline Dendrites & $2.4(7)$ & $29.3(7)$ & $66.7(8)$ & $0.9(4)$ & $0.4(1)$ & $0.3(8)$ \\
Light-grey phase & $22.6(6)$ & $24.5(8)$ & $14.4(8)$ & $12.0(3)$ & $3.3(3)$ & $23.2(7)$ \\
Dark-grey phase & $1.6(7)$ & $1.8(7)$ & $1.9(7)$ & $33.2(8)$ & $59.7(6)$ & $1.8(9)$ \\
\hline
\end{tabular}

Additionally, using the EDS technique, element distribution maps were obtained (Figure 3). The results confirmed the above-described analysis of the quantitative chemical composition for all phases. 


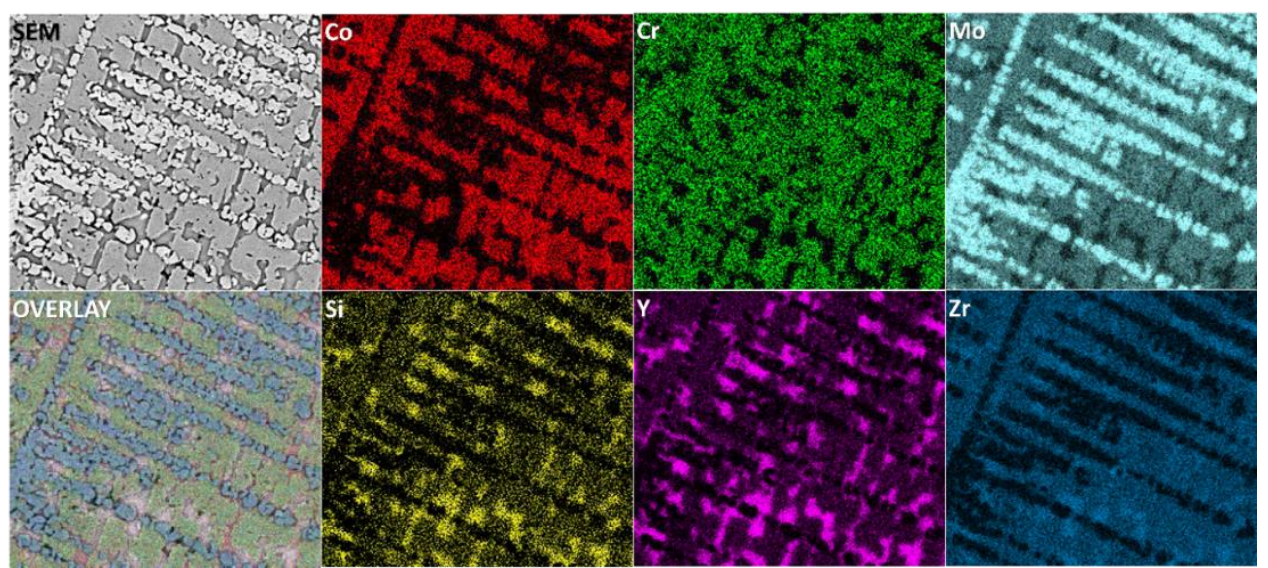

Figure 3. SEM energy-dispersive X-ray spectroscopy (EDS) elemental distribution maps in the studied alloy.

The EDS chemical composition analysis revealed that, for "dendrites" rich in $\mathrm{Cr}$ and Mo, they could correspond to the cubic $\mathrm{Cr}_{0.4} \mathrm{Mo}_{0.6}$ phase. This is confirmed by the above-described XRD phase analysis. The "light-grey" phase shows enrichment in $\mathrm{Co}, \mathrm{Cr}, \mathrm{Mo}, \mathrm{Si}$, and $\mathrm{Zr}$, which corresponds to the hexagonal $\mathrm{CoCrZr}$ and the cubic $\mathrm{CrMoZr}$ phases, as is given by the X-ray phase analysis. The last "dark-grey" phase reveals enrichment in Si and Y, which could correspond to the hexagonal $\mathrm{Si}_{3} \mathrm{Y}_{5}$ phase.

During solidification from a liquid state, $\mathrm{Cr}$ - and Mo-rich dendrites formed primarily due to the highest melting points in comparison to other alloying elements $\left(\mathrm{Cr}_{0.4} \mathrm{Mo}_{0.6}\right.$-like phase). $\mathrm{Co}, \mathrm{Cr}$, $\mathrm{Zr}$, and $\mathrm{Si}$ segregated in the interdendritic phases due to lower melting points and low miscibility, especially $\mathrm{Si}$ and $\mathrm{Y}$ with other alloying elements (CoCrZr, $\mathrm{CrMoZr}$, and $\mathrm{Si}_{3} \mathrm{Y}_{5}$ phases). The "light-gray" phase can be considered as a five-elemental high entropy alloy. Presence of the $\mathrm{Si}_{3} \mathrm{Y}_{5}$ phases observed as "dark-grey" areas can be considered as precipitates. The described elemental segregation of all elements stays in good agreement with the EDS elemental distribution maps (Figure 3).

\subsection{TEM Microstructure Analysis}

A detailed structure analysis was performed using HR TEM in order to examine the possible presence of the amorphous phase in the structure. Additionally, chemical composition using the EDS method was also examined. TEM observations confirmed the existence of amorphous areas revealed by the X-ray diffraction measurements. The wide amorphous regions are present in many regions of the specimen (Figure $4 \mathrm{a}, \mathrm{b})$. TEM observations revealed also a mixture of amorphous and nanocrystalline phases (denoted further as the "mixture area"; see Figure 4c-blue circle and Figure 4e) and the presence of purely nanocrystalline areas (Figure $4 \mathrm{~h}, \mathrm{i}$ ). The mutual coexistence of the amorphous and nanocrystalline areas in the material could be caused by the nonhomogeneous distribution of elements in the amorphous phase, which results in the faster crystallization of some areas. Crystallization could be also a result of ion beam polishing, which was reported for severely deformed NiTi-shape memory alloy [45]. Nevertheless, the ion beam energy was reduced in order to prevent heating of the specimen during ion polishing, but a crystallization of the amorphous phases could not be excluded. Such a claim can be supported by the fact that the nanocrystalline phase was not observed in the X-ray diffraction measurements. All the observed diffraction peaks were narrow, and only broad amorphous bumps were observed. From the nanocrystalline area, the high-resolution (HR) images were recorded. The observations confirmed presence of nanocrystallites of mixed phases in this area (Figure 4f). The average nanocrystallite size was approximately 23(11) $\mathrm{nm}$. A phase analysis based on the selected area electron diffraction patterns (SAED) indicated that the nanocrystalline phases present in both the nanocrystalline, as well as the mixture areas, are the cubic CrMoZr and hexagonal $\mathrm{Si}_{3} \mathrm{Y}_{5}$ (Figure 4e). The interplanar distances obtained from the fast Fourier-transformation image (FFT) 
(Figure 4g) confirmed the presence of those two phases. Additionally, the SAED patterns taken from the nanocrystalline area (Figure 4i) confirmed the presence of $\mathrm{CoCrZr}$ and $\mathrm{CrMoZr}$ phases with a small amount of the $\mathrm{Si}_{3} \mathrm{Y}_{5}$ phase. The phase analysis based on the FFT image (Figure $4 \mathrm{~g}$ ) and ring SAED pattern (Figure 4i) is in good agreement with TEM EDS chemical composition analysis (see Table 4). TEM EDS chemical composition measurements confirmed the presence of all alloying elements in all the studied areas.
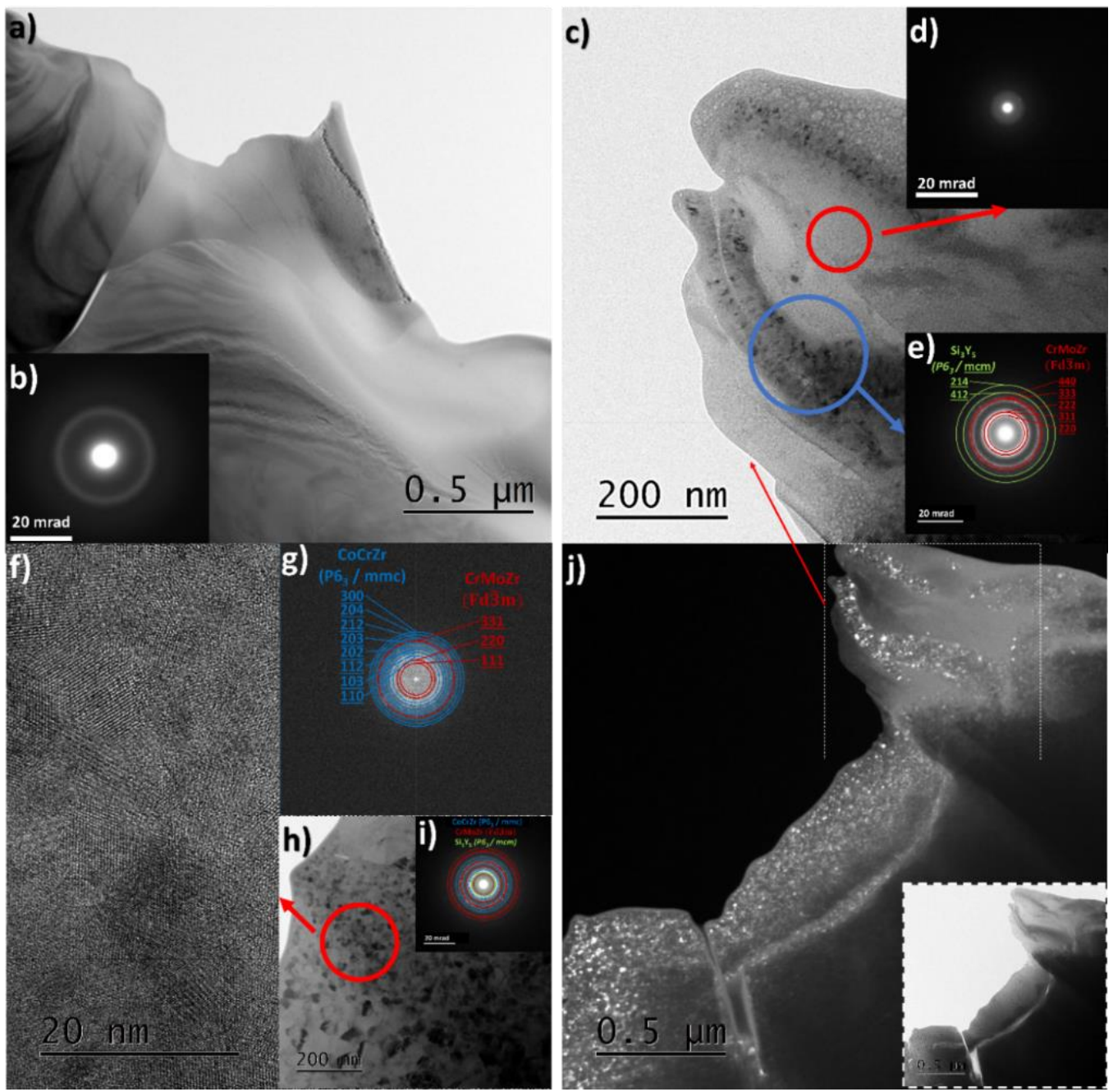

Figure 4. Bright field image of the amorphous area (a) with corresponding selected area electron diffraction (SAED) pattern (b), bright field of the amorphous area (red circle) (c) with corresponding SAED pattern (d), bright field of a mixture of amorphous and nanocrystalline area (blue circle) (c) with corresponding SAED pattern (e), high-resolution image nanocrystalline area (f) with Fourier-transformation image corresponding to HR image (g), bright field image of the nanocrystalline area (h) with corresponding SAED pattern (i), and bright field and dark field images of the amorphous and mixture of amorphous and nanocrystalline areas $(\mathbf{j})$.

Table 4. TEM EDS chemical composition (at.\%) of all phases in the studied alloys.

\begin{tabular}{ccccccc}
\hline Studied Area & Co & Cr & Mo & Si & Y & Zr \\
\hline Amorphous & $30.0(2)$ & $17.4(2)$ & $15.9(2)$ & $4.5(2)$ & $7.8(2)$ & $24.4(2)$ \\
Mixture & $20.6(2)$ & $16.8(2)$ & $10.7(1)$ & $16.5(1)$ & $18.8(1)$ & $16.6(1)$ \\
Nanocrystalline & $30.3(2)$ & $17.3(2)$ & $19.2(2)$ & $3.6(2)$ & $5.7(2)$ & $23.9(1)$ \\
\hline
\end{tabular}


It is highly probable that the presence of nanocrystallites, both in the nanocrystalline areas and mixture areas, could be the result of crystallization of places depleted in Si and Y, since Si and Y exhibit a strong amorphization ability and inhibit crystallization and grain growth. This can be also supported by the fact that amorphous areas are slightly enriched in those elements (TEM EDS analysis). The presence of nanometric sizes of crystallites could be also a result of Zr atoms distribution, which reduced the grain growth, as it was reported in the literature for CrMoZr alloy [46]. In these alloys, the addition of only $2 \%$ of $\mathrm{Zr}$ significantly reduced the grain size. The chemical composition of the "mixture area" exhibits also high amounts of $\mathrm{Si}$ and $\mathrm{Y}$, which means that $\mathrm{Si}_{3} \mathrm{Y}_{5}$ crystallites are present there.

\subsection{HT DSC Measurements}

In order to check the stability of phases in the studied alloy, DSC measurements at high temperatures were performed. Heating and cooling curves in the temperature range from RT up to $1350{ }^{\circ} \mathrm{C}$ are shown in Figure 5. For better visualization of the possible phase transformations in the studied alloy also, derivatives versus temperature are shown (inset-Figure 5).

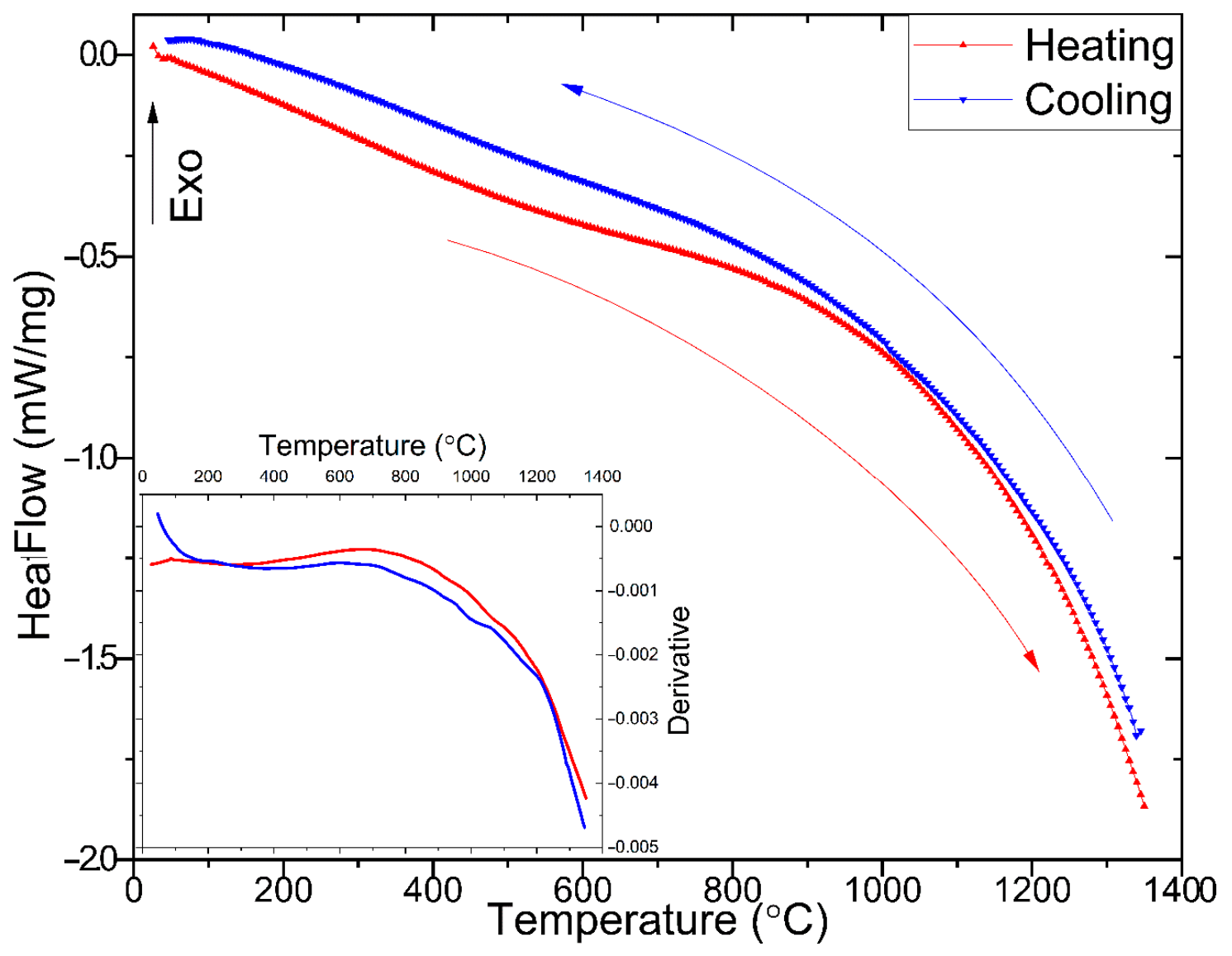

Figure 5. Differential scanning calorimetry (DSC) heating/cooling curves for the studied alloy.

It could be seen that the heating/cooling curves showed no phase transformation nor other thermal effects in the studied temperature range. The obtained results suggest the structural stability of the studied HEA alloy from RT up to $1350^{\circ} \mathrm{C}$. The reversible slope change (also visible on the derivative) on the DSC signal above $600^{\circ} \mathrm{C}$ may suggest a change in the heat capacity of the material. This could be a result of a small amount of the amorphous regions in the material and small enthalpy of crystallization. 


\subsection{Mechanical Properties}

Nanohardness tests were performed by the nanoindentation technique using a three-sided pyramid Berkovich tip. Sample polishing by $\mathrm{SiO}_{2}$ suspension caused a slight etching of the sample surface and revealed the "dendrites" and "light-grey" phases. Topography images $(10-\mu \mathrm{m} \times 10-\mu \mathrm{m}$ area for the dendritic-like phase and $40 \mu \mathrm{m} \times 40 \mu \mathrm{m}$ for the "light-grey" phase) were recorded using scanning mode. The nanoindentation points are labeled in the topography images (Figure 6). One can see that, for both observed phases, there are the traces of the tip inside the circles (Figure 6). For the microhardness and reduced Young's modulus calculations, only unambiguous indents belonging were taken into account.
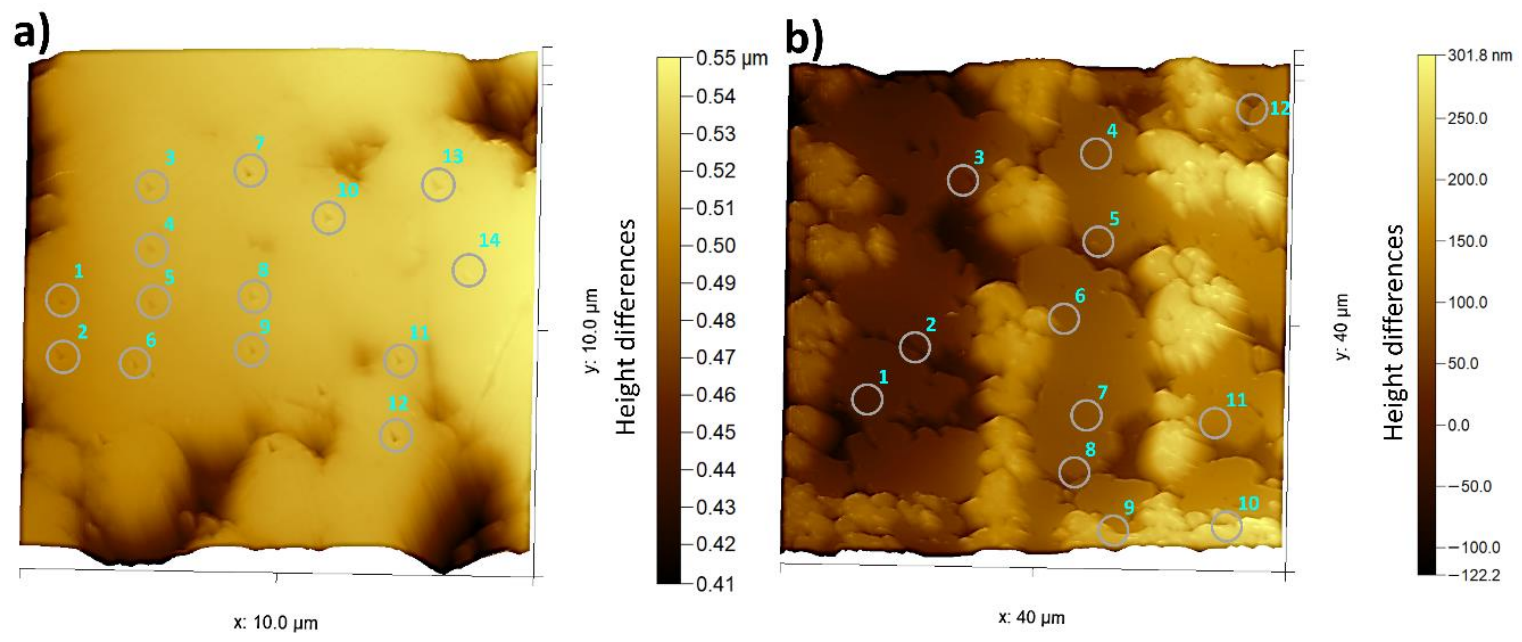

Figure 6. 3D topography image with assigned tip places for the dendritic-like phase (a) and for the "light-grey" phase (b).

The obtained values of nanohardness for the dendrites and "light-grey" phase are $\mathrm{H}_{\text {Dendrites }}=$ 13(2) GPa and $\mathrm{H}_{\text {Light-grey }}=18(1) \mathrm{GPa}$, respectively. The reduced Young's modulus for the dendritic-like and "light-grey" phases are $\mathrm{Er}_{\text {Dendrites }}=185(23) \mathrm{GPa}$ and $\mathrm{Er}_{\text {Light-grey }}=194(9) \mathrm{GPa}$, respectively. Both the studied phases differed distinctly in the nanohardness values, whereas the obtained values of the reduced Young's modulus are similar within the standard deviation. The obtained nanohardness and reduced Young's modulus values were compared with the literature data and presented in Table 5.

Table 5. Obtained nanohardness $(\mathrm{H})$ and reduced Young's modulus (Er) for the studied alloys in comparison to the literature-described high entropy alloy compositions.

\begin{tabular}{cccc}
\hline Chemical Composition & $\begin{array}{c}\text { Nanohardness } \\
\text { H (GPa) }\end{array}$ & $\begin{array}{c}\text { Reduced Young's Modulus } \\
\text { Er (GPa) }\end{array}$ & Reference \\
\hline $\begin{array}{c}\mathrm{Co}_{15} \mathrm{Cr}_{15} \mathrm{Mo}_{25} \mathrm{Si}_{15} \mathrm{Y}_{15} \mathrm{Zr}_{15} \\
\text { Light-grey }\end{array}$ & 17.88 & 193.81 & present study \\
\hline $\begin{array}{c}\mathrm{Co}_{15} \mathrm{Cr}_{15} \mathrm{Mo}_{25} \mathrm{Si}_{15} \mathrm{Y}_{15} \mathrm{Zr}_{15} \\
\text { Dendrites }\end{array}$ & 13.26 & 184.51 & present study \\
\hline $\begin{array}{c}\mathrm{Co}_{60.4} \mathrm{Cr}_{8.5} \mathrm{Mo}_{28.5} \mathrm{Si}_{2.6} \\
\text { Laves phase }\end{array}$ & 21.81 & 397.50 & {$[47]$} \\
\hline $\mathrm{Co}_{60.4} \mathrm{Cr}_{8.5} \mathrm{Mo}_{28.5} \mathrm{Si}_{2.6}$ & 21.80 & 398.00 & {$[48]$} \\
\hline
\end{tabular}


Table 5. Cont.

\begin{tabular}{|c|c|c|c|}
\hline Chemical Composition & $\begin{array}{c}\text { Nanohardness } \\
\text { H (GPa) }\end{array}$ & $\begin{array}{c}\text { Reduced Young's Modulus } \\
\text { Er (GPa) }\end{array}$ & Reference \\
\hline $\begin{array}{c}\mathrm{Co}_{60.4} \mathrm{Cr}_{8.5} \mathrm{Mo}_{28.5} \mathrm{Si}_{2.6} \\
\text { Solid solution }\end{array}$ & 13.78 & 310.52 & [47] \\
\hline $\mathrm{CoCrFeNiAl}_{0.3}$ & 12.28 & 197.44 & {$[49]$} \\
\hline $\begin{array}{c}\mathrm{Co}_{59.8} \mathrm{Cr}_{17} \mathrm{Mo}_{22} \mathrm{Si}_{1.2} \\
\text { Laves phase }\end{array}$ & 11.38 & 270.48 & [47] \\
\hline $\mathrm{Al}_{3} \mathrm{CoCrCuFeNi}$ & 10.50 & 260.00 & {$[50]$} \\
\hline $\begin{array}{c}\mathrm{CoCrFeNiY}_{0.3} \\
\text { Hexagonal phase }\end{array}$ & 10.50 & 215.00 & [51] \\
\hline $\mathrm{CoCrFeNiCuAl}_{2.5}$ & 9.20 & 174.30 & {$[52]$} \\
\hline $\mathrm{AlCoCrCuFeNi}$ & 8.13 & 172.00 & [53] \\
\hline CrMnFeCoNi & 7.64 & 252.00 & {$[54]$} \\
\hline $\begin{array}{l}\mathrm{Co}_{59.8} \mathrm{Cr}_{17} \mathrm{Mo}_{22} \mathrm{Si}_{1.2} \\
\text { Solid solution }\end{array}$ & 7.48 & 274.03 & [47] \\
\hline $\mathrm{CoCrFeNiCu}$ & 7.30 & 188.50 & {$[52]$} \\
\hline $\mathrm{Fe}_{38.5} \mathrm{Mn}_{20} \mathrm{Co}_{20} \mathrm{Cr}_{15} \mathrm{Si}_{5} \mathrm{Cu}_{1.5}$ & 6.83 & 192.60 & {$[55,56]$} \\
\hline $\mathrm{Fe}_{39} \mathrm{Mn}_{20} \mathrm{Co}_{20} \mathrm{Cr}_{15} \mathrm{Si}_{5} \mathrm{Al}_{1}$ & 6.38 & 205.70 & {$[55,57]$} \\
\hline $\mathrm{Fe}_{40} \mathrm{Mn}_{20} \mathrm{Co}_{20} \mathrm{Cr}_{15} \mathrm{Si}_{5}$ & 5.33 & 156.00 & {$[55,58]$} \\
\hline $\mathrm{Al}_{0.5} \mathrm{CoCrFeNi}$ & 4.64 & 220.84 & {$[59]$} \\
\hline $\mathrm{AlCrCuFeNi}_{2}(\mathrm{BCC})$ & 4.60 & 146.00 & {$[60]$} \\
\hline CrMnFeCoNi & 4.44 & 205.00 & {$[61]$} \\
\hline $\begin{array}{c}\mathrm{CoCrFeNiY}_{0.3} \\
\text { FCC phase }\end{array}$ & 3.30 & 190.00 & [51] \\
\hline $\begin{array}{l}\mathrm{CoCrFeNiY}_{0} \\
\text { FCC phase }\end{array}$ & 2.90 & 185.00 & [51] \\
\hline $\mathrm{AlCrCuFeNi}_{2}(\mathrm{FCC})$ & 2.80 & 207.00 & {$[60]$} \\
\hline NiFeCoCrMn & 1.88 & 190.21 & [62] \\
\hline
\end{tabular}

The reduced Young's modulus is comparable to the other high entropy alloys reported in the literature, like $\mathrm{CoCrFeNiAl}_{0.3}$ [49]. Nevertheless, the silicon and yttrium are present in all the phases observed in the microstructure and can cause a significant increase in hardness of the obtained $\mathrm{Co}_{15} \mathrm{Cr}_{15} \mathrm{Mo}_{25} \mathrm{Si}_{15} \mathrm{Y}_{15} \mathrm{Zr}_{15}$ high entropy alloy. Such a phenomenon was also reported for the $\mathrm{CoCrFeNiY}_{0.3}$ alloy [51], where a 3\% addition of $\mathrm{Y}$ increased both the nanohardness and Young's modulus. For Si containing a Tribaloy (Co-Cr-Mo-Si) [47], it was revealed that a 1\% Si addition also significantly increased the nanohardness and Young's modulus.

Due to the presence of a multiphase structure and amorphous regions, the studied material is brittle. This can be a drawback for their potential applications. However, the amorphous phase could be achieved by changes in the chemical composition, such as: increasing the concentration of Si and $\mathrm{Y}$ and their amorphization abilities in comparison to other alloying elements. On the other hand, modification of the production method in order to reach the critical cooling rate could increase the probability of the formation of the amorphous phase. 


\section{Conclusions}

The six-elemental high entropy $\mathrm{Co}_{15} \mathrm{Cr}_{15} \mathrm{Mo}_{25} \mathrm{Si}_{15} \mathrm{Y}_{15} \mathrm{Zr}_{15}$ alloy was obtained using the vacuum arc melting technique. The XRD phase analysis revealed the multiphase structure of the alloy, including the presence of the amorphous phase. SEM EDS and TEM EDS chemical analysis revealed that all six alloying elements are present in all the observed phases. The existence of amorphous regions was confirmed by TEM analysis. The TEM phase analysis of ring electron diffraction patterns confirmed XRD phase analysis. HT DSC measurements did not reveal any additional phase transformation during the heating (and cooling) up to $1350{ }^{\circ} \mathrm{C}$. The solid-state crystallization process was also not observed due to a relatively low amount of the amorphous phase. The mechanical tests revealed an increase of the reduced Young's modulus and nanohardness, which were caused by the Si and Y additions. The obtained results are comparable to data reported for the other high entropy alloys.

Nonetheless, the presented results showed that the examined alloy is a good candidate for metal glass material.

Author Contributions: Conceptualization, K.G., P.Ś., M.Z., and D.S.; methodology, K.G., M.Z., J.L., and P.Ś.; resources and material manufacturing, K.P. and R.A.; investigation, K.G., M.Z., J.L., and B.W.; writing-original draft preparation, K.G.; and data analysis, K.G., P.Ś. M.Z., G.D., and D.S. All authors contributed to writing-review and editing. All authors have read and agreed to the published version of the manuscript.

Funding: This research received no external funding.

Acknowledgments: We would like to thank Yong Yang and his collaborators from The Hong Kong University of Science and Technology for help in the calculations of excess mixing entropy to calculate the $\phi$ thermodynamic parameter.

Conflicts of Interest: The authors declare no conflict of interest.

\section{References}

1. Cantor, B.; Chang, I.T.H.; Knight, P.; Vincent, A.J.B. Microstructural development in equiatomic multicomponent alloys. Mater. Sci. Eng. A 2004, 375, 213-218. [CrossRef]

2. Yeh, J.-W. Overview of High-Entropy Alloys. In High-Entropy Alloys: Fundamentals and Applications; Gao, M.C., Yeh, J.-W., Liaw, P.K., Zhang, Y., Eds.; Springer International Publishing: Cham, Switzerland, 2016; pp. 1-19. ISBN 978-3-319-27013-5.

3. Steurer, W. Single-phase high-entropy alloys-A critical update. Mater. Charact. 2020, 162, 110179. [CrossRef]

4. Chen, T.K.; Wong, M.S.; Shun, T.T.; Yeh, J.W. Nanostructured nitride films of multi-element high-entropy alloys by reactive DC sputtering. Surf. Coat. Technol. 2005, 200, 1361-1365. [CrossRef]

5. Hsu, C.-Y.; Yeh, J.-W.; Chen, S.-K.; Shun, T.-T. Wear resistance and high-temperature compression strength of Fcc CuCoNiCrAl0.5Fe alloy with boron addition. Metall. Mater. Trans. A 2004, 35, 1465-1469. [CrossRef]

6. Huang, P.-K.; Yeh, J.-W.; Shun, T.-T.; Chen, S.-K. Multi-Principal-Element Alloys with Improved Oxidation and Wear Resistance for Thermal Spray Coating. Adv. Eng. Mater. 2004, 6, 74-78. [CrossRef]

7. Yeh, J.-W.; Lin, S.-J.; Chin, T.-S.; Gan, J.-Y.; Chen, S.-K.; Shun, T.-T.; Tsau, C.-H.; Chou, S.-Y. Formation of simple crystal structures in Cu-Co-Ni-Cr-Al-Fe-Ti-V alloys with multiprincipal metallic elements. Metall. Mater. Trans. A 2004, 35, 2533-2536. [CrossRef]

8. Yeh, J.-W.; Chen, S.-K.; Lin, S.-J.; Gan, J.-Y.; Chin, T.-S.; Shun, T.-T.; Tsau, C.-H.; Chang, S.-Y. Nanostructured High-Entropy Alloys with Multiple Principal Elements: Novel Alloy Design Concepts and Outcomes. Adv. Eng. Mater. 2004, 6, 299-303. [CrossRef]

9. Zhang, Y.; Zuo, T.; Cheng, Y.; Liaw, P.K. High-entropy alloys with high saturation magnetization, electrical resistivity, and malleability. Sci. Rep. 2013, 3, 1455. [CrossRef] [PubMed]

10. Gludovatz, B.; Hohenwarter, A.; Catoor, D.; Chang, E.H.; George, E.P.; Ritchie, R.O. A fracture-resistant high-entropy alloy for cryogenic applications. Science 2014, 345, 1153-1158. [CrossRef] [PubMed]

11. Lu, Y.; Dong, Y.; Guo, S.; Jiang, L.; Kang, H.; Wang, T.; Wen, B.; Wang, Z.; Jie, J.; Cao, Z.; et al. A promising new class of high-temperature alloys: Eutectic high-entropy alloys. Sci. Rep. 2014, 4, 6200. [CrossRef]

12. Senkov, O.N.; Wilks, G.B.; Miracle, D.B.; Chuang, C.P.; Liaw, P.K. Refractory high-entropy alloys. Intermetallics 2010, 18, 1758-1765. [CrossRef] 
13. Biesiekierski, A.; Wang, J.; Abdel-Hady Gepreel, M.; Wen, C. A new look at biomedical Ti-based shape memory alloys. Acta Biomater. 2012, 8, 1661-1669. [CrossRef] [PubMed]

14. Wang, S.P.; $\mathrm{Xu}, \mathrm{J}$. TiZrNbTaMo high-entropy alloy designed for orthopedic implants: As-cast microstructure and mechanical properties. Mater. Sci. Eng. C 2017, 73, 80-89. [CrossRef] [PubMed]

15. Glowka, K.; Zubko, M.; Swiec, P.; Prusik, K.; Dercz, G.; Stróz, D. Microstructure analysis of equiatomic multi-component $\mathrm{Ni}_{20} \mathrm{Ti}_{20} \mathrm{Ta}_{20} \mathrm{Co}_{20} \mathrm{Cu}_{20}$ alloy. Arch. Metall. Mater. 2019, 64, 785-789. [CrossRef]

16. Glowka, K.; Zubko, M.; Swiec, P.; Prusik, K.; Dercz, G.; Matyja, E.; Stróz, D. Microstructure of multi-component $\mathrm{Ni}_{35} \mathrm{Ti}_{35} \mathrm{Ta}_{10} \mathrm{Co}_{1} 0 \mathrm{Cu}_{10}$ alloy. Arch. Metall. Mater. 2019, 64, 715-719. [CrossRef]

17. Chen, C.H.; Chen, Y.J. Shape memory characteristics of (TiZrHf) ${ }_{50} \mathrm{Ni}_{25} \mathrm{Co}_{10} \mathrm{Cu}_{15}$ high entropy shape memory alloy. Scr. Mater. 2019, 162, 185-189. [CrossRef]

18. MacDonald, B.E.; Fu, Z.; Zheng, B.; Chen, W.; Lin, Y.; Chen, F.; Zhang, L.; Ivanisenko, J.; Zhou, Y.; Hahn, H.; et al. Recent Progress in High Entropy Alloy Research. JOM 2017, 69, 2024-2031. [CrossRef]

19. Miracle, D.B.; Senkov, O.N. A critical review of high entropy alloys and related concepts. Acta Mater. 2017, 122, 448-511. [CrossRef]

20. Takeuchi, A.; Amiya, K.; Wada, T.; Yubuta, K.; Zhang, W.; Makino, A. Entropies in Alloy Design for High-Entropy and Bulk Glassy Alloys. Entropy 2013, 15, 3810-3821. [CrossRef]

21. Xing, Q.W.; Zhang, Y. Amorphous phase formation rules in high-entropy alloys. Chin. Phys. B 2017, 26, 18104. [CrossRef]

22. Yang, Y.; Ye, Y.F.; Liu, C.T.; Lu, J.; Wang, Q. High-entropy alloy: Challenges and prospects. Mater. Today 2015, 19, 349-362. [CrossRef]

23. Nong, Z.-S.; Zhu, J.-C.; Cao, Y.; Yang, X.-W.; Lai, Z.-H.; Liu, Y. Stability and structure prediction of cubic phase in as cast high entropy alloys. Mater. Sci. Technol. 2014, 30, 363-369. [CrossRef]

24. Pitzer, K.S. The Nature of the Chemical Bond and the Structure of Molecules and Crystals: An Introduction to Modern Structural Chemistry. J. Am. Chem. Soc. 1960, 82, 4121. [CrossRef]

25. Dong, Y.; Lu, Y.; Jiang, L.; Wang, T.; Li, T. Effects of electro-negativity on the stability of topologically close-packed phase in high entropy alloys. Intermetallics 2014, 52, 105-109. [CrossRef]

26. Yang, X.; Zhang, Y. Prediction of high-entropy stabilized solid-solution in multi-component alloys. Mater. Chem. Phys. 2012, 132, 233-238. [CrossRef]

27. Ye, Y.F.; Wang, Q.; Lu, J.; Liu, C.T.; Yang, Y. The generalized thermodynamic rule for phase selection in multicomponent alloys. Intermetallics 2015, 59, 75-80. [CrossRef]

28. Wang, Z.; Huang, Y.; Yang, Y.; Wang, J.; Liu, C.T. Atomic-size effect and solid solubility of multicomponent alloys. Scr. Mater. 2015, 94, 28-31. [CrossRef]

29. Inoue, A. Stabilization of metallic supercooled liquid and bulk amorphous alloys. Acta Mater. 2000, 48, 279-306. [CrossRef]

30. Lu, Z.P.; Liu, C.T. Role of minor alloying additions in formation of bulk metallic glasses: A review. J. Mater. Sci. 2004, 39, 3965-3974. [CrossRef]

31. Choi-Yim, H.; Busch, R.; Johnson, W.L. The effect of silicon on the glass forming ability of the Cu47Ti34Zr11Ni8 bulk metallic glass forming alloy during processing of composites. J. Appl. Phys. 1998, 83, 7993-7997. [CrossRef]

32. Yi, S.; Park, T.G.; Kim, D.H. Ni-based bulk amorphous alloys in the Ni-Ti-Zr-(Si,Sn) system. J. Mater. Res. 2000, 15, 2425-2430. [CrossRef]

33. Inoue, A.; Murakami, A.; Zhang, T.; Takeuchi, A. Thermal stability and magnetic properties of bulk amorphous Fe-Al-Ga-P-C-B-Si alloys. Mater. Trans. JIM 1997, 38, 189-196. [CrossRef]

34. Yazici, Z.O.; Hitit, A.; Yalcin, Y.; Ozgul, M. Effects of minor $\mathrm{Cu}$ and Si additions on glass forming ability and mechanical properties of Co-Fe-Ta-B Bulk metallic glass. Met. Mater. Int. 2016, 22, 50-57. [CrossRef]

35. Zhang, T.; Kurosaka, K.; Inoue, A. Thermal and mechanical properties of Cu-based Cu-Zr-Ti-Y bulk glassy alloys. Mater. Trans. 2001, 42, 2042-2045. [CrossRef]

36. Lu, Z.P.; Liu, C.T.; Porter, W.D. Role of yttrium in glass formation of Fe-based bulk metallic glasses. Appl. Phys. Lett. 2003, 83, 2581-2583. [CrossRef]

37. Lu, Z.P.; Liu, C.T.; Carmichael, C.A.; Porter, W.D.; Deevi, S.C. Bulk glass formation in an Fe-Based Fe-Y-Zr-M (M = Cr, Co, Al)-Mo-B system. J. Mater. Res. 2004, 19, 921-929. [CrossRef]

38. Park, J.M.; Park, J.S.; Na, J.H.; Kim, D.H.; Kim, D.H. Effect of Y addition on thermal stability and the glass forming ability in Fe-Nb-B-Si bulk glassy alloy. Mater. Sci. Eng. A 2006, 435-436, 425-428. [CrossRef] 
39. Figueroa, I.A.; Davies, H.A.; Todd, I. High glass formability for Cu-Hf-Ti alloys with small additions of y and Si. Philos. Mag. 2009, 89, 2355-2368. [CrossRef]

40. Guo, S.; Liu, C.T. Phase stability in high entropy alloys: Formation of solid-solution phase or amorphous phase. Prog. Nat. Sci. Mater. Int. 2011, 21, 433-446. [CrossRef]

41. Skriver, H.L. Crystal structure from one-electron theory. Phys. Rev. B 1985, 31, 1909-1923. [CrossRef]

42. Wang, W.H. Roles of minor additions in formation and properties of bulk metallic glasses. Prog. Mater. Sci. 2007, 52, 540-596. [CrossRef]

43. Tong, Y.; Qiao, J.C.; Zhang, C.; Pelletier, J.M.; Yao, Y. Mechanical properties of Ti16.7Zr16.7Hf16.7Cu16.7Ni16.7Be16.7 high-entropy bulk metallic glass. J. Non-Cryst. Solids 2016, 452, 57-61. [CrossRef]

44. Takeuchi, A.; Chen, N.; Wada, T.; Yokoyama, Y.; Kato, H.; Inoue, A.; Yeh, J.W. $\mathrm{Pd}_{20} \mathrm{Pt}_{20} \mathrm{Cu}_{20} \mathrm{Ni}_{20} \mathrm{P}_{20}$ high-entropy alloy as a bulk metallic glass in the centimeter. Intermetallics 2011, 19, 1546-1554. [CrossRef]

45. Swiec, P.; Zubko, M.; Stróz, D.; Lekston, Z. Analysis of amorphous regions in severely marformed NiTi shape memory alloy. Int. J. Mater. Res. 2019, 110, 18-23. [CrossRef]

46. Lai, C.H.; Chen, W.C.; Tsai, P.H.; Ding, I.P. Effects of alloying additions in the CrMo underlayer on the grain size and magnetic properties of CoCrPt longitudinal media. J. Appl. Phys. 2003, 93, 8468-8470. [CrossRef]

47. Liu, R.; Yao, J.; Zhang, Q.; Yao, M.X.; Collier, R. Effects of Silicon Content on the Microstructure and Mechanical Properties of Cobalt-Based Tribaloy Alloys. J. Eng. Mater. Technol. Trans. ASME 2016, 138, 2-8. [CrossRef]

48. Yao, M.X.; Wu, J.B.C.; Liu, R. Microstructural characteristics and corrosion resistance in molten $\mathrm{Zn}$-Al bath of Co-Mo-Cr-Si alloys. Mater. Sci. Eng. A 2005, 407, 299-305. [CrossRef]

49. Liao, W.; Lan, S.; Gao, L.; Zhang, H.; Xu, S.; Song, J.; Wang, X.; Lu, Y. Nanocrystalline high-entropy alloy (CoCrFeNiAl0.3) thin-film coating by magnetron sputtering. Thin Solid Films 2017, 638, 383-388. [CrossRef]

50. Sun, Y.; Chen, P.; Liu, L.; Yan, M.; Wu, X.; Yu, C.; Liu, Z. Local mechanical properties of AlxCoCrCuFeNi high entropy alloy characterized using nanoindentation. Intermetallics 2018, 93, 85-88. [CrossRef]

51. Zhang, L.J.; Zhang, M.D.; Zhou, Z.; Fan, J.T.; Cui, P.; Yu, P.F.; Jing, Q.; Ma, M.Z.; Liaw, P.K.; Li, G.; et al. Effects of rare-earth element, $\mathrm{Y}$, additions on the microstructure and mechanical properties of $\mathrm{CoCrFeNi}$ high entropy alloy. Mater. Sci. Eng. A 2018, 725, 437-446. [CrossRef]

52. Ma, Y.; Feng, Y.H.; Debela, T.T.; Peng, G.J.; Zhang, T.H. Nanoindentation study on the creep characteristics of high-entropy alloy films: Fcc versus bcc structures. Int. J. Refract. Met. Hard Mater. 2016, 54, 395-400. [CrossRef]

53. Ganji, R.S.; Karthik, P.S.; Rao, K.B.S.; Rajulapati, K.V. Strengthening mechanisms in equiatomic ultrafine grained AlCoCrCuFeNi high-entropy alloy studied by micro- and nanoindentation methods. Acta Mater. 2017, 125, 58-68. [CrossRef]

54. Maier-Kiener, V.; Schuh, B.; George, E.P.; Clemens, H.; Hohenwarter, A. Nanoindentation testing as a powerful screening tool for assessing phase stability of nanocrystalline high-entropy alloys. Mater. Des. 2017, 115, 479-485. [CrossRef]

55. Sinha, S.; Mirshams, R.A.; Wang, T.; Nene, S.S.; Frank, M.; Liu, K.; Mishra, R.S. Nanoindentation behavior of high entropy alloys with transformation-induced plasticity. Sci. Rep. 2019, 9, 6639. [CrossRef]

56. Sinha, S.; Nene, S.S.; Frank, M.; Liu, K.; Mishra, R.S.; McWilliams, B.A.; Cho, K.C. Revealing the microstructural evolution in a high entropy alloy enabled with transformation, twinning and precipitation. Materialia 2019, 6, 100310. [CrossRef]

57. Nene, S.S.; Sinha, S.; Frank, M.; Liu, K.; Mishra, R.S.; McWilliams, B.A.; Cho, K.C. Unexpected strength-ductility response in an annealed, metastable, high-entropy alloy. Appl. Mater. Today 2018, 13, 198-206. [CrossRef]

58. Nene, S.S.; Frank, M.; Liu, K.; Sinha, S.; Mishra, R.S.; McWilliams, B.; Cho, K.C. Reversed strength-ductility relationship in microstructurally flexible high entropy alloy. Scr. Mater. 2018, 154, 163-167. [CrossRef]

59. Jiao, Z.M.; Chu, M.Y.; Yang, H.J.; Wang, Z.H.; Qiao, J.W. Nanoindentation characterised plastic deformation of a Al0.5CoCrFeNi high entropy alloy. Mater. Sci. Technol. 2015, 31, 1244-1249. [CrossRef]

60. Sun, Y.; Zhao, G.; Wen, X.; Qiao, J.; Yang, F. Nanoindentation deformation of a bi-phase AlCrCuFeNi 2 alloy. J. Alloys Compd. 2014, 608, 49-53. [CrossRef] 
61. Coury, F.G.; Wilson, P.; Clarke, K.D.; Kaufman, M.J.; Clarke, A.J. High-throughput solid solution strengthening characterization in high entropy alloys. Acta Mater. 2019, 167, 1-11. [CrossRef]

62. Wu, D.; Jang, J.S.C.; Nieh, T.G. Elastic and plastic deformations in a high entropy alloy investigated using a nanoindentation method. Intermetallics 2016, 68, 118-127. [CrossRef]

Publisher's Note: MDPI stays neutral with regard to jurisdictional claims in published maps and institutional affiliations.

(C) 2020 by the authors. Licensee MDPI, Basel, Switzerland. This article is an open access article distributed under the terms and conditions of the Creative Commons Attribution (CC BY) license (http://creativecommons.org/licenses/by/4.0/). 